\title{
Takashi Arima and his Transcendentalism
}

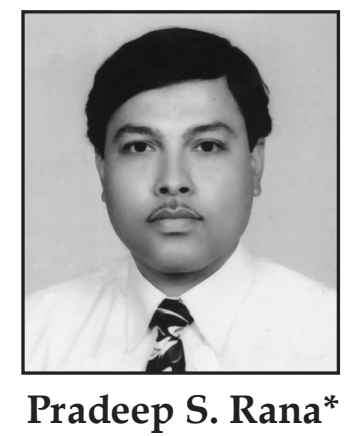

\begin{abstract}
This study is an enquiry into how self-realization and Transcendentalism in Arima's poetry diverges from those of the representative Western creative writers. It also explores and identifies effectiveness of rhetorical strategy in Arima's poetry, examines his method of self-realization through poetry writing, seclusion, and communion with the 'Super-soul' in relation to the Western practices. Data for the study were collected by means of structured questionnaires, FGD, books, journals, and online database. The study concludes that Arima's poetry reads so close to the Western poetry, and yet they are so far apart when it gets down to the real nitty-gritty of Transcendentalism and self-realization as received in the West.
\end{abstract}

Key words: Transcendentalism, rhetorical strategy, seclusion, communion, self-realization, Supersoul.

\section{Introduction}

Arima's transcendental practices through writing poetry and his first-hand experience of self-realization gained in the process, stir up a debate, as in other Eastern poetical works, on the nature and purpose of the oriental and occidental Transcendentalisms. A neat line of distinction crops up between these beliefs that inspire a new line of research into it. The study is geared to exploring subtle variance between them since they appear identical at times, and Arima's technique of spearheading self-realization through his creative life, a technique which is nearly missing in the Western literary tradition.

An experience, event, object or idea that is transcendental is extremely special and unusual and cannot be understood in ordinary ways (Cambridge International Dictionary of English, 1996). Some Transcendentalists in the West associate it with socialism, some with individualism, and some idealism. In his 1842 lecture "The Transcendentalist", Emerson suggested that the goal of a purely transcendental outlook on life was impossible to attend in practice (The Transcendentalist, 1842). Transcendentalism has been, since Emerson's time, deeply rooted in the American intellectual tradition, and has influenced a few growing literary movements in the U.S.A. One such representative literary movement is New Thought, fully dedicated to Emerson as its iconic Transcendentalist, which has influenced a large number of religious

* Associate Professor and HOD (English) Shanker Dev Campus, Tribhuvan University, Nepal 
authorities. However, the growth of Transcendentalism in the West bears much relation to Hinduism and Buddhism with the exception of a few Transcendentalists..

\section{Literature Review}

Walt Whitman (1926) mentioned in "Leaves of Grass" about mystery of nature and man's association with it. His belief in human life is totally spiritual and his thought about that in the universe is utterly divine. He thinks the meaning and purpose of Transcendentalism are embedded in civil obedience, self-reliance, and non-conformity. Miller (1978) argued that it must therefore be insisted upon that if Transcendentalism did not remain a disturbing force, the reason was not alone that America adopted it and made it orthodox, but also that it consumed, shattered, and destroyed its adherents. Transcendentalists like Margaret Fuller fled to Europe, to violence, and to death; Cranch took refuse in Florence and he cultivated dilettantism; Parker killed himself; Emerson dissolved into aphasia; Ripley subdued into disillusion; Hedge became a Harvard Professor, and Jones Very kept himself out of the lunatic asylum only by writing verified platitudes on the Atlantic cable.

According to Packer (2007), yet self-culture was only area of interest to the emerging group of Transcendentalists. They were the 'renewers of spiritual life' who believed in Unitarianism; therefore, they returned to nature where they could realize the presence of God as its creator. Finseth (2014) researched that the Transcendentalists received inspiration from overseas in the form of English and German romanticism, particularly the literature of Victor Cousin. None of them extrapolated from Buddhism anything transcendental; consequently, there was no link between Buddhism and Transcendentalism in their intellectual tradition.

Jing, Shua, \& Xinxin (2015) discovered that Transcendentalism - as the bridge between Eastern and Western culture, had played an important role in cultural communication. He also finds that both hemispheres have influenced each other's concepts of Transcendentalism, with much emphasis on the American cult of Transcendentalism. Friesner (2017) claimed that scholars of religion had often pointed to the Transcendentalists as progenitors of a distinct tradition of nature religion in the United States. He has found Emerson and Thoreau as nature writers influenced heavily by both Eastern and Western concepts of Transcendentalism. Emerson is one who possesses an idea that human beings, as both creators and created by environments, and nature are not the only universal reality or shared context that collects a diverse set of religious phenomena.

The majority of studies ---Whitman (1926), Finseth (2014), Packer (2007), and Miller (1978) --find the Western Transcendentalism influenced mostly by different versions of Christianity, and partly by Hinduism. The others --- Friesner (2017), and Jing, Shua, and Xinxin (2015) have found American Transcendentalism as a source of inspiration in China along with other Far Eastern countries except Japan, which do not bear direct relevance to the problem. The pilot study of the representative works of eminent scholars has revealed a noticeable research gap in the domain of the Western and the Eastern Transcendentalisms. They do not purport to be a compendium of origin, growth, and development of Transcendentalism in the world 
literature. However, the study attempts to answer the question of how creative life processes innate perception and divert mind, away from material attachment, to self-realization, a term understood in the west as 'the fact of using your skills and abilities and achieving as much as you can possibly achieve' (Cambridge International Dictionary of English, 1996), but not as 'the intelligence to renew his work where he ended his last life' (Prabhupad, 2014).

Arima's poetry composed since mid-fifties, if analyzed them from the perspective of the Transcendentalists, imparts a sense of self-realization, much the same as "Night Train to Lisbon", a philosophical novel by Pascal Mercier, in which a real journey to the self is dramatized in such a way that there is hardly any human being who does not feel lonesome and realize inner self. In a way life coincides with an onion and hence intriguing like it: if life is measured and unfolded by time, an onion is unfolded by peeling off its multiple layers one at a time. Nothing intriguing is left with life and the onion once the core is revealed ---- all that is left with life is the vista of years and that with an onion is the layers that shape what it looks like. However, life constantly makes an arduous journey to where it originates, and where its full identity and perfection are deposited. Creative life is devoted entirely to transcending the individual self by continually reaching beyond the limits of space and time in pursuit of the universal self (Ikeda, 1996). "A journey to the Real" and "Peregrinateur Solitaire" feature his selected anecdotal poems which encompass a myriad of verbal portraits, intertwined with rich imagery and subtleties of artistry, of contemporary civilizations of the world, which capture volatile personalities and drive them very close to the realities of overall trends of living and the parameters of vast modern developments. They do not even articulate his feelings on reincarnation which is a recurring theme in James Joyce's "Ulysses" and "Walt Whitman's "Leaves of Grass" ----- the recurring theme in his books being the realization of the ultimate truth of literature and life.

\section{Methods}

\section{Participants}

The study concentrates, going somewhat further, on a small group of intellectuals in Kathmandu to maintain a degree of reliability required for the study. Thirty Nepali readers and writers of literature in English and Nepali, and twenty academicians in the pertinent field, having knowledge and insight into the data desired, constitute the sample for the study. A set of fifty structured questionnaires is prepared to achieve the research objectives, and are administered to both male (36) and female (14) Nepali readers and writers of literature in English and Nepali, and academicians.

\section{Design}

The study is founded on a research design --- ancillary to a logical literary task undertaken for a useful academic purpose --- to ensure that the data garnered from various sources answer the research questions and achieve the research objectives. The documentary evidence required to justify the key literary issue, framed in the domain of oriental literature, is derived inductively from both primary and secondary sources. The nature and purpose of 
the study pertaining to Arima's esoteric poetry adopt a tactful approach to the implications of his transcendental voyage. A set of fifty structured questionnaires are administered to both male (36) and female (14) Nepali readers and writers of literature in English and Nepali, and academicians. The tools and techniques employed to collect primary and secondary data consist of questionnaires, FGD, and published and unpublished literary writings available at libraries, literary institutions, data base, and respondents' places. As regards the selection of sites for study, Kathmandu is chosen as a focal area where all participants are easy to approach and co-ordinate for FGD. The study is descriptive and analytical.

The objectives of the study are: (a) to estimate the effectiveness of rhetorical strategies in Arima's poetry; (b) to explore Transcendentalism in his poetry in relation to that in the West; (c) to examine seclusion and communion as coincidental events in his poetry.

\section{Procedure}

All questionnaires are piloted to test before they are distributed. In a questionnaire, a list of fifteen short answer and ten objective type questions are presented for data collection. All twenty five questions are on effectiveness of rhetorical strategies in Arima's poetry, his transcendental experiences, and solitude and communion from the perspective of a readerresponse criticism. Ten objective type questions are based on segmentation of the topic under study: the Eastern and Western Transcendentalisms, poetry writing and self-realization, use of rhetorical devices in poetry, and solitude and communion. In the first session, only thirty five questionnaires along with copies of select poems and bio-data of the poet are administered to the Nepali writers in English and Nepali as other sampled writers have been difficult to reach, so only in the second session the remaining questionnaires and copies of select poems and bi-data of the poet are administered to them. The completed questionnaires have been coded, and the responses have been transferred to the summary sheet by using ticks to ease the problem of data processing. Out of the sampled academicians, only three who have agreed to participate in the FGD are invited to a fixed venue at a fixed time in Kathmandu, but the other participants are invited to a different venue and time in the second round. The items on the agenda are inspired by the objectives of the study, and the items discussed are summarized and transferred to the summary sheet for verification and data processing. The study will benefit people from all walks of life and creative writers.

\section{Results}

Seventy five percent of the respondents vouch for Arima's use of effective rhetorical strategy in his poetry to communicate with his readership. The poetic imagery in the poem "Strange Darkness", in which he writes a line 'Hand, hand, hand...' (Arima, 1996), represents a crowd of people at Gandhi Airports. The title of the poem is metaphorical that substitutes a crowd of strange dark-complexioned people, and tells the readers so much by saying so little. The majority of his poems feature similar rhetorical techniques, with a first person narrator, to argue his points logically, in the most general way, with a much wider readership. They embrace the Aristotelian appeals ---- logos, ethos, and pathos ---- to ward off obstacles in approaching the issue of self-realization in the context of everyday living and creative writing. 
His other poems ---."Homeless", "The Memory of the Twilight”, "Earth Spirit Communion", "Survival Songs", "Legend", "The Beginning of the End", "Breaking up", "In the Fog", "My Stamp", "Sounds of Asia", etc. ---- have received his powerful voices and are basically effective to present his persuasive arguments, and take ethical and pathetic approaches to the readership for illuminating his conceptual framework in which self-realization and poetry writing run in parallel to develop and transmit his Transcendental experiences. His another poem "Legend", for example, is ironical, unfolds the story in flashback, and draws an analogy between the Nipponese and the Western balance of power in Asia and Europe during the post-1940 period. The other poems like "Darkness Strange", "Cattle in India", "The Beginning of the End", "Two Pigeons", and "Sound of Asia" are a few such examples, which are rhetorically composed with those devices. In "My Stamp", personification is a prominent device as in other poems like "In the Fog" and "The Machine".

Transcendentalism in Arima's poetry writing is diametrically opposite to that in the Western poetry writing. His Transcendentalism has led him to seclusion and bent his mind to selfrealization which never betrayed him from the path to success. In contrast, Transcendentalism in the West has galvanized most poets and writers into seeking shelter in nature and, in the process of transformation, some of them have ended up in prison, some in committing suicidal acts, and some ended up their days in violence and death, and some in overwork, etc. Transcendentalism has basically nothing to do with those human acts. Arima's seclusion and communion have concocted a setting in his mind where he delves into consciousness in search of his point of origin and true identity. What is self-realization for him is not the same for most poets and writers in the West. Arima's self-realization denotes his personal attempt to relate a 'part' with the 'whole', that is, to unite one's soul with the 'Super-soul'. This is where the Western rendition of self-realization takes a divergent path.

\section{Discussion}

\section{Transcendentalism and Self-realization}

In the remote depth of Arima's philosophy of life, a simple truth stands alone and high above all other things. He is as simple a man as a winter fog in Japan. Unlike an early crow in a fog, he is fully monitored through the fog by the inner lights he has cherished time after time in his life, and has, therefore, no scruples about remaining as truthful as a crow in a metaphorical poem "In the Fog": I was born in a fog/ Brought up in a fog,/ And now I live in a fog (Arima,1993). The poem serves as a backdrop with poetic imagery that unfolds his transcontinental odyssey towards undulating, indeterminate, and formidable regions of life and death, all unexplored and unknown to him. Arima is different in "Journey to the Real". As yet, during the mission, nothing has misled him anywhere. He comes home quietly to live in a fog again, but with a remarkable variation on the central theme this time: Standing on the bluff of the cape, / I am in the fog, / And all I can do is flicker like a lighthouse (Arima, 1993). Unlike Transcendentalist Margaret Fuller, Ranch, Florence, Parker, Thoreau, Emerson, Ripley, etc, Arima does not drive his odyssey to an end. 
He is but a harbinger of the world community of bards, who defies logically ---- in "A Message From the Unknown" ---- invention, discovery, and high-tech phenomena restricting our sixth sense to a wider range of hypotheses and hallucinations: Can you give birth/ To an object of fresh life/ By communicating with someone beyond yourself? / Can you create/ A self that stands splendidly alone/ By sending out your own ideas? (Arima, 1993) In contrast, the western Transcendentalists only write about 'communicating with someone beyond yourself', but they do not internalize its value. The narrator in Edgar Allen Poe's story "Never Bet the Devil Your Head" (1841) ridicules their writings by calling them "metaphor-run lapsing into mysticism for mysticism's sake," and call it a "disease" (Transcendentalism, 2018). Arima sounds even more radical, in hushed tones and malcontent in action, to scientific community: Do you feel / Signals from the universe? / Can you write down / inspiration from the world? (Arima, 1993) These are the vexed questions the poet has directed them to Transcendentalists. And, no doubt, the leading question is the very act of 'feeling signal from the universe' which is distinctly beyond the reach of ordinary people.

With some outlandish ideas and experiences harbored during the dangerous course of 'a journey to the real', or poetry writing, Arima seems to have tried several ways to live in communion with the 'Super-soul since he is closer to the ultimate truth of life. This is indeed part and parcel of Arimaesque ethical standard of living in a fog, flickering all the time like a lighthouse. Invariably, while he is away from home on 'a journey to the real', he unveils, in the poem "Night in the Gobi", a superb feeling of similar nature: A long time ago, on a night like this / I felt a hut near the top of Mount Fuji, flashlight in hand / Approaching a sharp ridge in total darkness, / I had the illusion I was ascending to the stars (Arima, 1993). At the end of the poem, it is equally vigorous in its implication and thought-provoking in its presentation of rhetorical strategies like pathos, symbols, and imagery, where doleful faces are served with spiritual illumination: A flock of sheep returned from the pasture / Sleep quietly together on the wide grassy field / under this tremendous starry sky / Let the family, sheep, and I / Rest silently (Arima, 1993). This is an exquisite idyll of fine spiritual experience, and the idyllic structure of spiritual items unfolds supreme pleasure of the 'silent rest'. Here is also an ample ground for those who wish to delve into spiritual matters irrespective of other Arimaesque precepts. Such is, in fact, the reality of situation, and such is the beauty of truth. The creation of a work of art takes place within spatial boundaries, but through the process of creating, the soul of the artist seeks union with that ultimate reality, what might be called cosmic life. A living work of art is life itself, born from the dynamic fusion of the self (the microcosm) and the universe (the macrocosm) (Ikeda, 1996). Such link between creativity and 'Supersoul', which is palpable in Arima's writing, is at variance with the Western transcendental experience and creativity.

\section{Solitude and Communion}

Not surprisingly Arima states with confidence his capacity to communicate, from a small corner of the universe, with the departed spirits: I feel even happier than the time / I felt extremely happy for the shortest of moments / In a very small corner of this huge universe / To be able to communicate with a soul/ Like a comet from far away (Arima, 1995). The simile 
'like a comet' in the last line elucidates concept of incorporeal communication whereby one particle of the spirit remains in touch with the other or vice versa, and, in the end, all particles merge into the 'Super-soul', the unique source of origin for all particles. Farther from this truth nothing is real, nothing is immortal. Here, Walt Whitman's contemplation of his self is close to Arima's when he writes in "Leaves of Grass": But I, / turning to thee O soul, / thou actually me (Whitman,1926).... However, it does not refer to the same self-realization as practiced and understood by Arima through his meditative technique of writing poetry; it is Whitman under the mere influence of Hindu religion.

In the poem "Ambulance Avenue", Arima poses a rhetorical question on a hackneyed subject: life and death. However, every night the question happens to arise in his mind on a street of Matsuyama where he hears clearly the 'pee-paw' siren of a local ambulance transporting 'people on the verge of death' to the hospital. He says ------ Sometimes I can't fall straight back to sleep, then / I lie awake and think about my death (Arima, 1993) ------that death alone appears in his life, which is nothing but a real journey to the real in that, while developing intimacy with it, he has cultivated in his solitude the real cause for enlightenment which has come to his life in due course. In his 1842 lecture "The Transcendentalist," he (Emerson) suggested that the goal of a purely transcendental outlook on life was impossible to attend in practice: "You will see by this Transcendentalism is the Saturnalia or excess of Faith; the presentiment of a faith proper to man in his integrity, excessive only when his imperfect obedience hinders the satisfaction of his wish (Transcendentalism (2018)." However, this is not always the case.

Unlike American Transcendentalists, Arima has similar brilliant idea enshrined pathetically in his poems. He is helping himself to take steps towards the 'beginning of the end', towards the light against darkness, towards the truth against falsity, and towards immortality against mortality. This motive is inherent in his metaphorical poem "The Outskirts of Delphi": Midday, under an overcast sky drawing towards darkness / I'm a stranger left all alone (Arima, 1995). The corresponding motive over and above other factors coincides logically with it once more in the poem "A Short Odyssey": Oh Mousha, say a prayer / For this guy who has drifted here / From a distant country in Asia (Arima, 1995). Thoreau's book "Walden" emphasizes the importance of solitude, contemplation, and closeness to nature in transcending the "desperate" existence that, he argues, is the lot of most people (Walden, 2018). Here, what Thoreau means by solitude does not signify a prelude to communion with the 'Super-soul'. Many conscious minds are more sensitive and only a few are less, depending on the milieus they live in. One such example is Bronson Alcott who writes, following the collapse of Fruitl and, a community based on Utopian ideals inspired in part by transcendentalism, "None of us were prepared to actualize practically the ideal life of which we dreamed (Emerson, 2018).

\section{Conclusion}

Equipped with effective rhetorical strategies, Arima's poetry inculcates Transcendentalism in his readership, and divulges the core values of self-realization in human life, which is 
significantly at variance with the western concept of Transcendentalism and self-realization. Most of the western Transcendentalists have missed self-realization as a process of knowing one's self and dovetailing it with the 'Super-soul' through the transcendental meditation. They have taken refuse in nature from socio-political degeneration, but they have disapproved of self-realization as a part of eastern mysticism, so the thrust of their version of Transcendentalism is on the nature as a site of supernatural manifestations and favorable to creative writing. However, Arima's return to nature is not basically a scheme to immerse in writing poetry, but it is a medium that connects him to creative writing and communion with the 'Super-soul'. In the secluded part of nature, he feels an urge to write poems and, through writing them, he goes transcendental. He is one of those rare people who have arrived at due process following his 'journey to the real' and its continuation in the other half of his life. Much of his poetry brings to light simplicity in expression, sincerity in narration, and, above all, exploration of ultimate truth of life. By and large, Arima's literary creation has bestowed a new dimension on the contemporary creative writing and Transcendentalism.

\section{References}

Arima, T. (1993).Journey to the Real: Selected poems of Takashi Arima. New York: Weatherhill, Inc.

Arima, T. (1995). Peregrinateur Solitaire. Parish: Nouvelle Plelade

Cambridge International Dictionary of English. (1996). Cambridge, England: Cambridge University press.

Finseth, I. (2014). The emergence of Transcendentalism: American Studies. Virginia: University of Virginia press. Friesner, N. (2017).A Transcendentalist Nature Religion.Religions: Journal of Department of Religious Studies, Brown University, 8(8), 130. Retrieved from http:/ / www.mdpi.com.

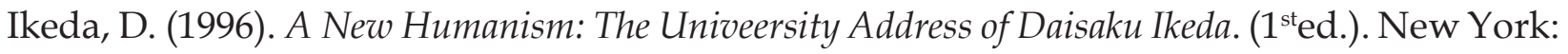
Weatherhill, Inc.

Jing, S., Shua, L. , \& Xinxin, D. (2015). A Literature Review of Recent Research on Transcendentalism in China and Abroad. CSCanada, 7, 135-138. Doi: 10.

Miller, P. (Ed.). (1978). The Transcendentalists: An Anthology (4 $4^{\text {th }}$ ed.). London: Massachusetts \& Harvard University Press.

Packer, B. (2007). The Transcendentalists. New York: The University of Georgia Press.

Prabhupada, B. (2014). Bhagavad-gitaAs It Is. (2 ${ }^{\text {nd }}$ ed.). Mumbai, India: The Bhaktivedanta Book Trust.

The Transcendentalist (1842). In American Transcendentalism Web. Retrieved June 9, 2018 from https:/ / arvhive.vcu. edu/english/eng web/ tra...

Transcendentalism (2018, May 11). In Wikipedia: Free Encyclopedia: Retrieved June 25,2018 from https://en. m. Wikipedia. org> wiki> trans.

Whitman, W. (1926). Leaves of Grass. Garden City, New York: Doubleday \& Company. 